\title{
The Strength Properties of Fibre Reinforced Self Compacting Concrete
}

\author{
N. BOZKURT ${ }^{a, *}$ AND S. YAZICIOĞLU ${ }^{b}$ \\ ${ }^{a}$ Bitlis Eren University, Civil Engineering Department, 13000, Bitlis, Turkey \\ ${ }^{b}$ Gazi University, Technolgy Faculty, Civil Engineering Department, Ankara, Turkey
}

\begin{abstract}
This paper reports results of an experimental study of the strength properties of fibre reinforced self-compacting concrete (FRSCC). For this aim, a control self-compacting concrete and 24 FRSCCs were designed, applying fresh self-compacting concrete criteria tests. In the design of FRSCC, four steel and two polypropylene synthetic fibres of different lengths and aspect ratios were used. These fibres were used alone and in combinations with two and four of these fibres. In this way, not only the effect of single fibre and the synergy effect of hybrid fibres, but also the size and concentration effect of fibres, which had different ratios in total fibre volume, were investigated. In the design process, Portland cement and fly ash were used as the binder and the powder material. The compressive and flexural-tensile strength tests were employed at the age of 3, 7, 28, 56 and 90 curing days, to determine the strength properties of FRSCCs. Moreover, ultrasound pulse velocity test was also performed on all concrete series at the same ages.
\end{abstract}

DOI: 10.12693/APhysPolA.132.775

PACS/topics: 62.20.--x, 81.05.Ni, 81.70.Bt, 89.20.Kk

\section{Introduction}

Fibre reinforced concrete (FRC) and self-compacting concrete (SCC) are two important types of novel concretes. Both of them have big advantages and benefits in civil engineering industry. Moreover, both of them have disadvantages in comparison with each other. SCC has bleeding problem in the design process and fresh state, while FRC has problems with concrete placement into the moulds and problem of passing between the tight rebars in the fresh state.

To solve these problems, there is a continuous research by the scientist and experts. Sahmaran et al. [1] investigated the workability properties of hybrid FRSCC and stated that SCC, in comparison wit FRC, is a relatively new kind of concrete technology due to its advantages of good flow ability. Akcay and Tasdemir [2] investigated mechanical behaviour and fibre dispersion of hybrid steel fibre reinforced self-compacting concrete. Sezer et al. [3] investigated the dependence of impact resistance of steel fibre reinforced concrete and has stressed that the influence of steel fibre inclusion is clearly observed in impact resistance of concrete. Persson [4] reported a comparison between mechanical properties of SCC and the corresponding properties of normal concrete.

Of course, SCC and FRC are not the only special concretes or concrete research improvements. There are a lot of special concrete technology and special concrete researches in literature. Foam concrete, lightweight concrete and heavy concrete can be given as examples [5-7]. In this study, the strength properties of FRSCC created as combination of two special concretes, the SCC and FRC,

*corresponding author; e-mail: nbozkurt@beu.edu.tr were investigated at different curing ages. FRSCCs were produced with six different fibres and fly ash (FA) powder, which is a waste material.

\section{Materials and methods}

Type I cement and fly ash were used as binder and powder material, respectively, in the design process. The specific gravity, Blaine and strength values of cement and FA are $3.10 \mathrm{~g} / \mathrm{cm}^{3}, 3382 \mathrm{~cm}^{2} / \mathrm{g}, 51.7 \mathrm{~N} / \mathrm{mm}^{2}$ and $2.50 \mathrm{~g} / \mathrm{cm}^{3}, 1343 \mathrm{~cm}^{2} / \mathrm{g}, 18.1 \mathrm{~N} / \mathrm{mm}^{2}$, respectively. All aggregates were natural river aggregates, obtained from Elazığ in Turkey. High performance, third generation hyper-plasticiser (HP), providing high level of water decreasing and long-time of workability, was used as chemical addition. Used fibre inclusions and general information about used fibres are presented in Table I.

Steel fibre amount was $50 \mathrm{~kg} / \mathrm{m}^{3}$, while amount of polypropylene synthetic fibres (PSF) was $600 \mathrm{gr} / \mathrm{m}^{3}$. The mix proportions of all designed FRSCCs are given in Table II. Based on the Table II, FRSCCs were produced and evaluated in fresh state. It has been proven in an earlier report that they were fulfilling the SCC criteria. In the framework of the aim of this paper, the strength properties of FRSCC were investigated by employing the compressive and flexural-tensile strength tests and the ultrasound pulse velocity (UPV) test on FRSCCs, designed and produced according to Table II.

\section{Results and discussion}

The compressive strength results were similar to each other because the only variable in the FRSCC mix designs was fibre and fibre inclusion percentages for single and hybrid design. Compressive strength results of single-FRSCCs (1-7 series) increased when the fibre length and aspect ratio decreased in the concrete mix. 
Fibre inclusion in the concrete series and general fibre properties. Employed fibre geometries: waved (W), straight fibrillate $(\mathrm{SF})$, hookend $(\mathrm{H})$, straight $(\mathrm{S})$.

\begin{tabular}{|c|c|c|c|c|c|c|}
\hline Series & \multicolumn{2}{|c|}{ Fibre inclusion } & Series & \multicolumn{3}{|c|}{ Fibre inclusion } \\
\hline 1 & \multicolumn{2}{|c|}{$100 \% \mathrm{~S} 1$} & 13 & \multicolumn{3}{|c|}{$50 \% \mathrm{~S} 3+50 \% \mathrm{~S} 4$} \\
\hline 2 & \multicolumn{2}{|c|}{$100 \% \mathrm{~S} 2$} & 14 & \multicolumn{3}{|c|}{$50 \% \mathrm{P} 1+50 \% \mathrm{~S} 4$} \\
\hline 3 & \multicolumn{2}{|c|}{$100 \% \mathrm{~S} 3$} & 15 & \multicolumn{3}{|c|}{$25 \% \mathrm{~S} 1+75 \% \mathrm{~S} 2$} \\
\hline 4 & \multicolumn{2}{|c|}{$100 \% \mathrm{~S} 4$} & 16 & \multicolumn{3}{|c|}{$25 \% \mathrm{~S} 1+75 \% \mathrm{~S} 3$} \\
\hline 5 & \multicolumn{2}{|c|}{$100 \% \mathrm{P} 1$} & 17 & \multicolumn{3}{|c|}{$25 \% \mathrm{~S} 1+75 \% \mathrm{~S} 4$} \\
\hline 6 & \multicolumn{2}{|c|}{$100 \% \mathrm{P} 2$} & 18 & \multicolumn{3}{|c|}{$25 \% \mathrm{~S} 2+75 \% \mathrm{~S} 3$} \\
\hline 7 & \multicolumn{2}{|c|}{$200 \% \mathrm{P} 2$} & 19 & \multicolumn{3}{|c|}{$25 \% \mathrm{~S} 2+75 \% \mathrm{~S} 4$} \\
\hline 8 & \multicolumn{2}{|c|}{$50 \% \mathrm{~S} 1+50 \% \mathrm{~S} 2$} & 20 & \multicolumn{3}{|c|}{$25 \% \mathrm{~S} 3+75 \% \mathrm{~S} 4$} \\
\hline 9 & \multicolumn{2}{|c|}{$50 \% \mathrm{~S} 1+50 \% \mathrm{~S} 3$} & 21 & \multicolumn{3}{|c|}{$25 \% \mathrm{P} 1+75 \% \mathrm{~S} 3$} \\
\hline 10 & \multicolumn{2}{|c|}{$50 \% \mathrm{~S} 1+50 \% \mathrm{~S} 4$} & 22 & \multicolumn{3}{|c|}{$25 \% \mathrm{P} 1+75 \% \mathrm{~S} 4$} \\
\hline 11 & \multicolumn{2}{|c|}{$50 \% \mathrm{~S} 2+50 \% \mathrm{~S} 3$} & 23 & \multicolumn{3}{|c|}{$25 \% \times(\mathrm{S} 1+\mathrm{S} 2+\mathrm{S} 3+\mathrm{S} 4)$} \\
\hline 12 & \multicolumn{2}{|c|}{$50 \% \mathrm{~S} 2+50 \% \mathrm{~S} 4$} & 24 & \multicolumn{3}{|c|}{$25 \% \times(\mathrm{S} 3+\mathrm{S} 4+\mathrm{P} 1+\mathrm{P} 2)$} \\
\hline & P1 & P2 & S1 & S2 & S3 & $\mathrm{S} 4$ \\
\hline $\begin{array}{l}\text { Spec. } \\
\text { gravity }\end{array}$ & 0.92 & 0.92 & 7.85 & 7.85 & 7.85 & 7.17 \\
\hline $\begin{array}{l}\text { Length } \\
\text { [mm] }\end{array}$ & 55 & 13 & 60 & 35 & 30 & 6 \\
\hline $\begin{array}{c}\text { Equiv. } \\
\text { diam. }[\mathrm{mm}]\end{array}$ & 0.80 & 22 mic. & 0.75 & 0.55 & 0.55 & 0.15 \\
\hline $\begin{array}{c}\text { Aspect } \\
\text { ratio }\end{array}$ & 70 & - & 80 & 64 & 55 & 40 \\
\hline $\begin{array}{l}\text { Tensile } \\
\text { strength }\end{array}$ & 400 & 400 & 1050 & 1150 & 1100 & 2000 \\
\hline Geometry & $\mathrm{W}$ & $\mathrm{SF}$ & $\mathrm{H}$ & $\mathrm{H}$ & $\mathrm{H}$ & $\mathrm{S}$ \\
\hline
\end{tabular}

The lowest strength value was obtained in series 1 , having the longest and thickest steel fibre (S1), while the highest strength value was obtained in the series 4 , having micro steel fibre (S4).

Sahmaran and Yaman [8] reported that using micro steel fibres instead of macro fibers resulted in higher compressive strength. On the contrary, Song and Hwang [9], Yazıcı et al. [10] stated that the compressive strength was increasing when the fibre aspect ratio and fibre percentage were increased. As another finding, there was no essential improvement in compressive strength with fibre addition in the report by Kayalı et al. [11] and Quanbing and Beirong [12].

In this study, if Fig. 1 is carefully analysed, an improvement is seen in compressive strength in single-FRSCCs, when the steel fibre length and aspect ratio are decreased. Series 5, 6, having single-PSFs, gave very close compressive strength result, compared to control SCC (K). Besides, series 7 including 200\% P2 gave 4.48\%, 8.70\%, $5.17 \%, 4.69 \%$ and $4.25 \%$ lower compressive strength in comparison with series $\mathrm{K}$ at each curing day.

Similarly, Sabir [13], Chen and Liu [14] have emphasized that PSF usage decreased the compressive strength of concrete. As for compressive strength of the hybridFRSCC, again an improvement was observed when the long and thick fibres ratios were decreased in total fibre volume. After a close look at Fig. 1, it is noticed that the higher compressive strength values were obtained
Mix proportions of control SCC and FRSCC (\%).

\begin{tabular}{c|c|c|c|c|c|c|c}
\hline \hline Mix & Cement & FA & Water & $\begin{array}{c}\text { Fin. } \\
\text { agr. }\end{array}$ & $\begin{array}{c}\text { Coar. } \\
\text { agr. }\end{array}$ & Fibre & Hp** \\
\hline 1 & 11.3 & 6 & 20 & 32.65 & 29.41 & 0.64 & 1.25 \\
2 & 11.3 & 6 & 20 & 32.63 & 29.43 & 0.64 & 1.25 \\
3 & 11.3 & 6 & 20 & 32.62 & 29.44 & 0.64 & 1.25 \\
4 & 11.3 & 6 & 20 & 32.60 & 29.40 & 0.70 & 1.25 \\
5 & 11.3 & 6 & 20 & 32.65 & 29.40 & 0.65 & 1.25 \\
6 & 11.3 & 6 & 20 & 32.91 & 29.75 & 0.065 & 1.10 \\
7 & 11.3 & 6 & 20 & 32.87 & 29.70 & 0.13 & 1.15 \\
8 & 11.3 & 6 & 20 & 32.64 & 29.42 & 0.64 & 1.25 \\
9 & 11.3 & 6 & 20 & 32.64 & 29.42 & 0.64 & 1.25 \\
10 & 11.3 & 6 & 20 & 32.60 & 29.44 & 0.66 & 1.25 \\
11 & 11.3 & 6 & 20 & 32.62 & 29.44 & 0.64 & 1.25 \\
12 & 11.3 & 6 & 20 & 32.60 & 29.44 & 0.66 & 1.25 \\
13 & 11.3 & 6 & 20 & 32.60 & 29.44 & 0.66 & 1.25 \\
14 & 11.3 & 6 & 20 & 32.60 & 29.43 & 0.67 & 1.25 \\
15 & 11.3 & 6 & 20 & 32.63 & 29.43 & 0.64 & 1.25 \\
16 & 11.3 & 6 & 20 & 32.63 & 29.43 & 0.64 & 1.25 \\
17 & 11.3 & 6 & 20 & 32.60 & 29.41 & 0.68 & 1.25 \\
18 & 11.3 & 6 & 20 & 32.63 & 29.43 & 0.64 & 1.25 \\
19 & 11.3 & 6 & 20 & 32.60 & 29.41 & 0.68 & 1.25 \\
20 & 11.3 & 6 & 20 & 32.60 & 29.41 & 0.68 & 1.25 \\
21 & 11.3 & 6 & 20 & 32.63 & 29.43 & 0.64 & 1.25 \\
22 & 11.3 & 6 & 20 & 32.60 & 29.41 & 0.68 & 1.25 \\
23 & 11.3 & 6 & 20 & 32.63 & 29.43 & 0.65 & 1.25 \\
24 & 11.3 & 6 & 20 & 32.62 & 29.45 & 0.63 & 1.25 \\
$25 *$ & 11.3 & 6 & 20 & 32.95 & 29.75 & - & 1 \\
\hline$*$ Control SCC (K). ${ }^{* *}$ Hyper-plasticiser has been & added
\end{tabular}

to mixes based on cement percentage.

from the hybrid-FRSCC series, including smaller macro fibres, together with micro fibres. The best compressive strength was obtained from the series 20 (84.81 MPa).

There were no considerable differences in results obtained from the UPV tests (Fig. 2). These results also verify and support the compressive strength test results. The big differences were only observed between the FRSCC series containing steel fibres and PSFs. The usage of PSF gave lower UPV results. Furthermore, UPV values have increased when the micro steel fibre percentage increased in the total fibre volume. When the fibre length and aspect ratio decreased, the number of fibre grains filling the same volume increased. This situation led to increasing fibre contact with each other within the concrete matrix. Consequently, UPV values increased in hybrid-FRSCCs, containing micro steel fibres.

Figure 3 presents the results of flexural tensile strength tests of FRSCCs. Normally, all designed concretes gained flexural tensile strength with increasing curing ages. However, jumps in the the change of the flexural tensile strength were seen, when the curing age had increased from 7 to 28 and from 56 to 90 days. These jumps are due to facts that the standard curing age of concretes is 28 days, and FA powder affects the concrete strength properties after 90 days [15]. 


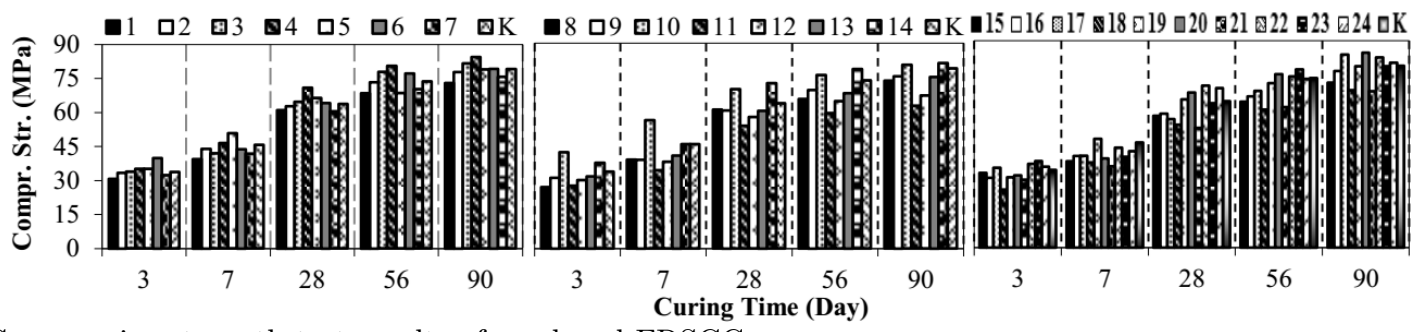

Fig. 1. Compressive strength test results of produced FRSCC.

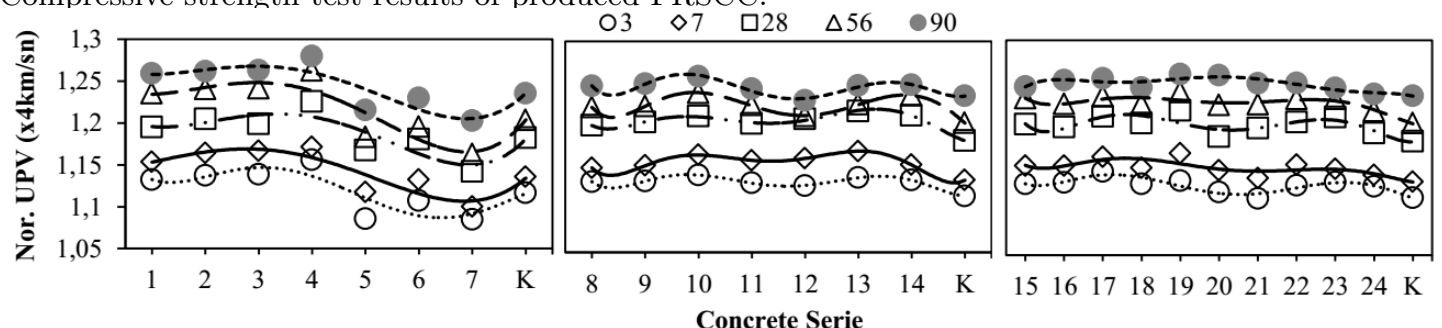

Fig. 2. Normalised UPV test results of produced FRSCC.

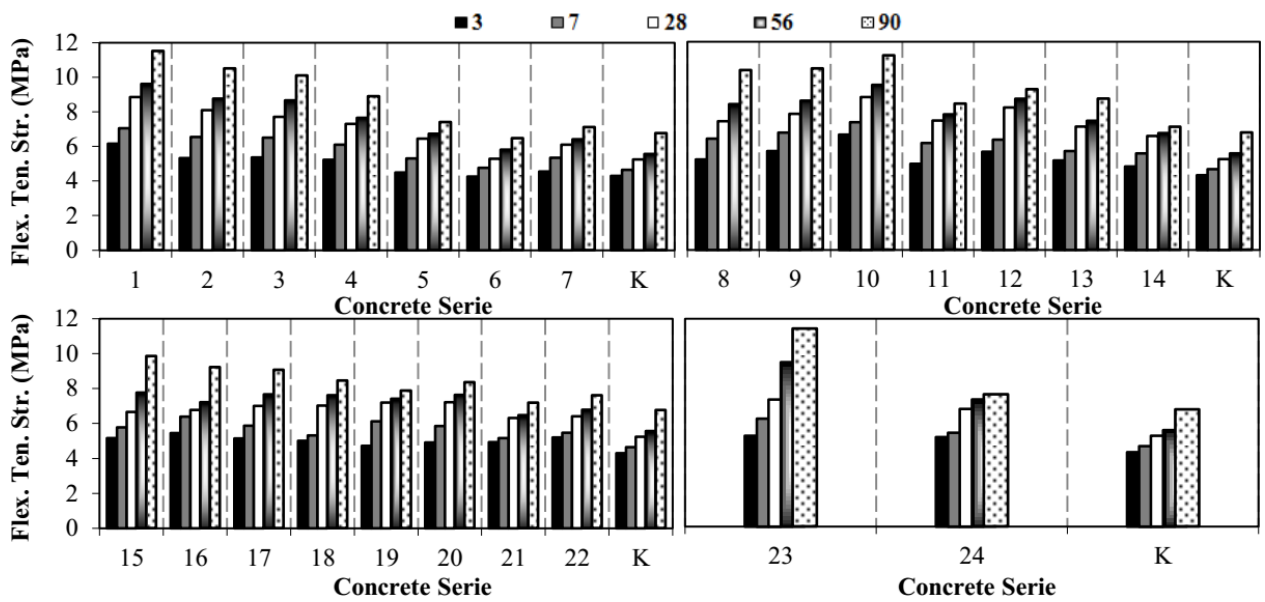

Fig. 3. Flexural tensile strength test results of produced FRSCC.

Unlike the compressive strength, the flexural tensile strength had dramatically decreased when fibre length and aspect ratio were decreased in the concrete mixes. According to strength result after 90 curing days for series 1 , when the fibre length was decreased in the ranges of $42 \%, 50 \%$ and $90 \%$, flexural tensile strength decreased in the range of $9 \%, 12 \%$ and $23 \%$, respectively.

PSF usage in the FRSCC design has caused small improvement on the flexural tensile strength. Moreover, the worst result $(6.46 \mathrm{MPa})$ was obtained in the series 6 , including micro PSF, while the best result (11.5 MPa) was obtained in the series 1 , having longest fibre (S1). However, this fibre is $60 \mathrm{~mm}$ long and it is very thick. These characteristics lead to problems in the fresh state of concrete.

When Fig. 3 is carefully analysed, it is seen that very close results were obtained in the series 8, 9, 10 and 23 . These results show the synergy effect of hybrid fibres. In the first hybrid-FRSCC group (8-14), the highest flexural strength result (series 10, 11.2 $\mathrm{MPa}$ ) provided $58 \%$ improvement in comparison with $\mathrm{K}$ in 90 curing days. In addition, a very close strength value was obtained from the series 23 (11.41 MPa, 61\% improvement), including four different fibres in the total fibre volume. This result also verifies the synergy effect of fibres having different lengths and aspect ratios. Yun et al. [16] have stressed that hybrid fibre usages provides higher splitting and flexural tensile strength than the single fibre usage.

\section{Conclusions}

Better strength properties were obtained with the production of FRSCC. When the fibre length and aspect ratio were decreased in the single fibre inclusion and the longer fibres concentration was decreased in the hybrid fibre inclusion, the results of compressive strength and UPV test had improved, while the flexural tensile strength results have worsened. Higher flexural tensile strength values were obtained with the employment of hybrid fibre in the FRSCCs. The best flexural tensile strength was $11.42 \mathrm{MPa}$ in concrete with hybrid fibre inclusion after 90 curing days (series 23). Steel fibre inclusion have provided more improvement in UPV test while PSF inclusion was affecting it negatively. FA powder inclusion (35\% by volume) brought economical and eco-friendly production of FRSCCs. Moreover, it has resulted in the strength improvement after 90 curing days. 


\section{Acknowledgments}

The authors of this paper appreciate funding from FIRAT University Scientific Research Projects Unit (Project No: FÜBAP1416). The authors would like to express their gratitude to BEKAERT and SIKA TURKEY for providing the fibres and chemical additives used in this study.

\section{References}

[1] M. Sahmaran, A. Yurtseven, I.O. Yaman, Build. Environ. 40, 1672 (2005).

[2] B. Akcay, M.A. Tasdemir, Construct. Build. Mater. 28, 287 (2012).

[3] G.İ. Sezer, Ş. Yazıcı, A. Sezer, Acta Phys. Pol. A 128, B-37 (2015).

[4] B.A. Persson, Cement Concrete Res. 31, 193 (2001).

[5] M. Davraz, S. Kilincarslan, M. Koru, F. Tuzlak, Acta Phys. Pol. A 130, 469 (2016).

[6] M. Davraz, Ş. Kilinçarslan, H. Ceylan, Acta Phys. Pol. A 128, B-184 (2015).
[7] Ş. Kılınçarslan, Acta Phys. Pol. A 128, B-469 (2015).

[8] M. Sahmaran, I.O. Yaman, Construct. Build. Mater. 21, 150 (2007).

[9] P.S. Song, S. Hwang, Construct. Build. Mater. 18, 669 (2004).

[10] Ş. Yazıcı, G. İnan, V. Tabak, Construct. Build. Mater. 21, 1250 (2007).

[11] O. Kayali, M.N. Haque, B. Zhu, Cement Concrete Compos. 25, 207 (2003).

[12] Y. Quanbing, Z. Beirong, Cement Concrete Res. 35, 2360 (2005).

[13] B.B. Sabir, Mag. Concrete Res. 53, 163 (2001).

[14] B. Chen, J. Liu, Cement Concrete Res. 35, 913 (2005).

[15] T.Y. Erdoğan, Concrete, METU Development Foundation Publishing and Communication, Ankara 2003 (in Turkish).

[16] H.-D. Yun, I.-S. Yang, S.-W. Kim, E. Jeon, C.-S. Choi, H. Fukuyama, Mag. Concrete Res. 59, 257 (2007). 